\title{
Alcohol Use Disorder in a Culture That Normalizes the Consumption of Alcoholic Beverages: The Conflicts for Decision-Making
}

\author{
Guilherme (G) Messas and Maria Julia (MJFR) Soares
}

\subsection{Introduction}

Disorders associated with the use of alcohol always reflect the cultural values of the societies in which they occur. This applies equally to Brazil, a country whose culture minimizes the risks of consumption. Current representations of alcohol in the media and in music lead to the invisibility of the social risks of alcohol and hinder the effectiveness of the laws that regulate its sale and use. For example, many young people initiate the use of alcohol with the consent of their parents, although the country's law prohibits minors under the age of 18 from drinking alcohol. Thus, consumption begins to be normalized within family relationships.

Given this cultural liberality in relation to the use of alcohol, what dilemmas arise for the therapeutic management of patients with harmful use of alcohol? Here, we briefly address two questions: What are the values that permeate the treatment of individuals who seek a healthier relationship with alcohol consumption? How does culture permeate therapeutic choices?

The following narrative tells the story of a Brazilian we will call Bruno, who values family, health, and work. After a hospitalization for complications due to the use of alcohol, he tries to stay healthy, but cannot maintain abstinence. Together with his wife, he goes to see the psychiatrist.

G. (G) Messas ( $₫)$

Department of Mental Health, Santa Casa de Sao Paulo School of Medical Sciences,

São Paulo, Brazil

Postgraduate Program on Phenomenological Psychopathology, Santa Casa de São Paulo

School of Medical Sciences, São Paulo, Brazil

e-mail: guilherme.messas@fcmsantacasasp.edu.br

M. J. (MJFR) Soares

Postgraduate Program on Phenomenological Psychopathology, Santa Casa de São Paulo School of Medical Sciences, São Paulo, Brazil

Hospital do Servidor Público Estadual de São Paulo, São Paulo, Brazil

e-mail: majufrs@gmail.com 


\subsection{Narrative: The story of Dra Sousa and Her Patient, Bruno}

Bruno (fictitious name) patient who receives treatment for Alcohol Use Disorder. He sought medical care for the first time with symptoms of Alcohol Abstinence Syndrome, tremors, psychomotor agitation and altered level of consciousness. In addition to this diagnosis, alcoholic hepatitis was also found. He was hospitalized and remained in a psychiatric ward for 10 days; after clinical stabilization, he continued treatment in the hepatology and psychiatric outpatient clinics of the service that assisted him during hospitalization. In a regular and punctual manner, the patient always went to the medical consultations, accompanied by his wife, Lucia (fictitious name).

At that time, Bruno was very frightened by the impact of alcohol consumption on his health and decided to stop drinking. He does not remember when he first drank; he tells us that since he was a child when his father came home, he offered wine to his three children. He tells, lightly, at once, that his mother was irritated by his father's habit. In response, he made the children drunk. Bruno doesn't know how old he was at the time, but he believes that this story occurred when he was around 7 years old. Neither Bruno and Lucia understand Bruno's father to be an alcoholic, because he did not cause "embarrassment", but they list some of his maternal uncles who are alcoholics, one of whom died of liver cirrhosis.

As an adult, Bruno started to drink after working hours, always in the same place, Lucia's brother's car jet wash, close to his house, with the same people that he calls "drinking buddies". He consumed beer, accompanied by cachaça (brazilian spirit). He often stopped at the car jet wash after work and drank heavily, When he arrived at home he used to be already drunk. As he usually drove back home he put himself and other in risk. Normally he went to work the next day with a hangover. He tells us that he did not consider it right to go to work after consuming alcoholic beverages, and that is why he only drank after work. Even among heavy drinkers in Brazil, drinking and working are assumed as a serious misbehavior.

After the hospital admission and the return to routine, Bruno could not maintain the abstinence achieved with the doctor. And, in a follow up consultation, he said that he had drunk six cans of beer at home at night, only once. "Sorry", he said, "I would no longer consume alcohol". Thus, he remained abstinent for 2 months. However, within a couple of months, he had started drinking alcohol again, about three to four cans of beer, at his house, during the night, daily.

Bruno says he is still very concerned about his health. He comes to appointments monthly, takes the physical examinations and tests requested, and takes all medications prescribed regularly. Lucia's presence and care are also important, helping him with the dates of his return and organizing the medicines. Bruno believes that his wife is the person he can trust the most.

Bruno tells us that, in his opinion, his current use of alcohol is not as harmful as before. He stopped going to the car jet washer and meeting with his "drinking buddies". Currently, he only uses beer at home at night and does not mix beer with any other drink or with cachaça, as he did before. He believes that beer is lighter than other drinks, because when he drinks beer, he believes, he never gets drunk, and 
everybody drinks beer. Bruno also emphasizes in the consultation that he no longer goes to work with a hangover, he believes, in this way, there is no impact of the drink on his work or his life. And he always thinks that the day will come when he is able to stop drinking forever, but he does not want to make that decision now.

Lucia does not hide her concerns about Bruno. She says that her husband minimizes his alcohol consumption, and that although the changes reported by him are true, she is afraid that he will increase the amount of alcohol he takes, returning to previous levels. Lucia does not believe there is anything more that can be done for Bruno to help him to decide to stop using alcohol, she said: "I try to talk to him, he never listen, he always do, what he wants to do, so he drinks anyway". She believes that it would not be helpful to readmit him, because she does not believe that he will remain abstinent after discharge. And she requests that the medical follow-up, with the medications and returns, remain frequent, because she is always concern about bruno's health, warning that the so that her husband is close to the care he needs for his health-and if he needs further hospitalization, he will already be linked to the institution, and to the physician who has helped him.

Dra. Sousa (fictitious name), after the hospitalization, started to see Bruno. She receives him in a welcoming way, listening to his complaints, his symptoms, his relationship with alcohol, with his medication, and with his wife. She then sees Lucia, asking her to describe her complaints about Bruno's behavior and her concerns. After understanding what is important for each of them in relation to Bruno's treatment, Dra. Sousa explains the available treatment options.

Dr Sousa bases her advice on available evidence-based medicine guidelines. She proposes pharmacological treatment with topiramate, recommended in the treatment of Alcohol Use Disorder, to reduce the urge to use alcohol, and naltrexone, which reduces the pleasure sensation generated by alcohol. Two other therapeutic strategies proposed for the patient were refused: Bruno chose not to start using disulfiram, a substance that induces discomfort when the patient uses alcohol, he explain that he does not intend to feel any harm if he decides to drink, and refuse to do Group Therapy, offered by their service. Bruno explains that he does not want to use disulfiram at that time because he had decided not to abstain. As to Group Therapy he believed that he would not benefit currently from therapy of any kind, because he did not feel comfortable talking about his problems with people he does not trust, and did not believe that therapy could help him stop drinking.

\subsection{Values Arising and Clinical Care}

Dra. Sousa began the approach to this case by identifying the fundamental values of the patient, which could support the establishment of treatment: the presence of Bruno's family, of his wife, Lucia, his concern for his health care and well-being, and his wish to perform well at work. These factors had all been important in helping Bruno to reduce his alcohol intake. Also important were his wife's, Lucia's, care and supportive concern. It is usual in Brazil that wives support their husbands in alcoholism, supporting them in their appointments, helping with the administration 
of medications, and supporting the changes that the treatment imposes, like Lucia did with Bruno. This support is maintained even when there is a case of marital violence against women. Alcoholism plays an important role in gender-based violence in Brazil, and despite the existence of a specific criminal law to combat violence against women (Lei Maria da Penha), this is still a widespread practice in Brazil [1]. The change in mood provoked by the state of drunkenness is understood by some men-especially in the lower classes-as a supplement of courage to offend and attack their wives. Surprisingly, the offended women often take on the role of caregivers of the husband after being persecuted. The main reason for this is the interpretation that her man is a good man, only alcohol drives him mad, and it is her responsibility to keep the man away from this source of risk.

It was also essential to identify the values that were in conflict with these supportive values. Dr. Sousa's view, based on scientific evidence, was that the best course for Bruno would be complete abstinence. However, Bruno expressed no desire for this option. In the same way, Lucia, his wife, however, much she wished for Bruno's abstinence, did not believe that he would be willing to take this course at that time. In short, the couple's shared wish was that Bruno's health should continue to be cared for, even though he was still using alcohol.

Dra Sousa thus aimed to secure a clinically effective approach to case management by taking into account her patient's values even though these conflicted with her evidence-based view that he should become abstinent. As described above in the case history, she prescribed naltrexone to reduce Bruno's desire for alcohol (by reducing the pleasure he experienced while drinking), together with topiramate, an anticonvulsant, to control his compulsion to drink. This approach thus drew on Dr. Sousa's knowledge of the relevant evidence-based medical information to propose an approach to treatment that respected the patient's value of reducing alcohol use. Similarly, she understood her patient's refusal of group psychotherapy and the use of disulfiram as an expression of the value Bruno placed on continuing to drink.

This reflects a person-centered approach to treatment in that all decisions were made in partnership between Dr. Sousa, Bruno, and his wife, Lucia. Consistent with her values as a clinician, however, Dr. Sousa continued to emphasize the harmful effects on health of alcohol use, always included Lucia in consultations, and remained alert to the possible adverse effects of continued alcohol use on Bruno's work.

\subsection{The Influences of Culture on This Story}

Like Bruno, most Brazilians who drink begin to use alcohol before the age of 18, the age at which the use of alcoholic beverages becomes legal. There is a culture that beer is a lighter beverage, not bringing the same risks as other alcoholic beverages, such as cachaça, the typical Brazilian spirit. Beer is often considered a nonalcoholic beverage, as in publicity regulation [2]. Beer is the most consumed alcoholic 
beverage in the country [3]. It is also commonly the case that alcohol is consumed after work, at home, even if in front of minors, contrary to the Brazilian law. It is also common for people to go back to the same establishments to consume alcohol, often in environments not suitable for alcohol consumption, as in Bruno's case when he went back time and again to his 'drinking buddies' in his brother-in-law's jet wash. When people go to the jet wash, they usually go by car; if they drink, they could be a risk to themselves and other people.

It is believed that alcoholics are only those individuals who abuse alcohol (which means for many brazillians causing embarrassment to others), while daily overconsumption is not widely recognized as a harmful habit. Bruno's family, for example, when he was a child, did not see their father's behavior (giving wine to his children) as harmful to their health. Alcohol consumption is trivialized by common expressions such as cervejinha (little beer), vinhozinho (little wine), and barzinhos (little bar). In the same way, excessive drunkenness is even actively cultivated, often as a sign of virility.

Alcohol consumption is embedded in the daily life of Brazilians, expressed in popular music of all different musical styles: for example, in the brega " $\ldots$ and to kill sadness only at a bar table, I will take them all, I will get drunk..."; in the samba "... I drink yes, I am living, there are people who do not drunk and are dying..."; and in the sertanejo "... drowning in alcohol, sound of the car in the stem...". On television, in advertisements known as "Skol (beer brand), the beer that goes down round" or "Brahma (beer brand), the number 1".

In addition, the main laws that regulate the use of alcohol in Brazil are ineffective, such as the law that criminalizes the sale of alcohol to minors under 18 years of age, or permissive, such as the determination that a beverage is only considered an alcoholic beverage for advertising purposes if it has more than $13 \mathrm{GL}$ of alcohol [2]. In conclusion, Brazilian society is very poorly protected and enlightened about the harm related to the use of alcohol in the country [4]. For this reason, a recent initiative has been launched, introducing Value-Based-Practice as a tool for alcohol regulation in Brazil [5].

\subsection{Conclusions}

Substance misuse emerges from different psychopathological experiences involving personal and cultural values, which highlights the need to consider the different values when determining treatment [6]. VBP is a tool for assessing personal and cultural values and increases the effectiveness of management when it involves complex and conflicting values [7].

In the previous pages, we showed an example of how alcoholism is interpreted in Brazil, by a case of a patient, Bruno, his wife, Lucia, and the clinician, Dr. Souza. We could see how the pattern of use of Bruno jeopardizes him, his relevant others, as well as population in general. His behavior regarding alcohol shows us that, for Brazilian culture, especially in men, the most important topic defining alcoholism is 
any compromise to the professional role. Other natural consequences of alcohol misuse of, as inflicting harm on others, as, for instance, intramarital violence, drinking and driving, or drinking in front of minors, are not ranked among "alcohol problems".

Intramarital violence related to alcohol is a frequent theme in Brazilian culture. Usually, offended wives are implicated in the treatment of their male aggressors at least at the beginning of the husband's alcoholism. As we could see in this case, Lucia was fundamental for the continuity of Bruno's treatment. Her role was to simultaneously accept the patient's desire - a desire not to be abstinent-and to point out the issue to be addressed by the clinician, for example, to tell the clinician that he could be drinking more than he suggested. Thus, Lucia plays the role of bringing back the truth to the treatment and helps in the clinical process. This attribute of telling another narrative (distinct from the patient's narrative) to the clinician and, as a consequence, helping the clinician to be aware of what is happening in a treatment is usually a female role in Brazil.

The narrative exemplifies the application of an approach based on the basic principles of VBP [7]. First, the decisions were shared between the patient, the main stakeholder, and the medical professional who assists them. Bruno, part of the Brazilian culture, exhibited a behavior that minimized alcohol consumption, not considering the usual hangover as a problem related to alcohol and stating that if he does not have clear problems working with alcohol, he sees no reason to suspend the use of beer, the main drink consumed in the country. Thus, Dr. Souza, despite understanding that abstinence could be the best option for the patient to avoid new liver complications, decided, together with the patient and the stakeholder, to implement harm reduction [3]. In more severe cases of alcoholism in Brazil, the decisionmaking process on the problem related to alcohol includes several stakeholders, in order to reach a consensus on the treatment of the patient. The Brazilian culture adopts the idea that the misuse of severe alcohol is not exclusively an issue of the individual and, as a consequence, cannot be addressed by an isolated individualist perspective. A clear evidence of this perception is the great increase in the number of lay and religious Therapeutic Communities (TCs) in contemporary Brazil. In these, abstinence is the main target of care, based on a whole reorganization of community life [8].

The medications prescribed to Bruno were chosen based both on patient values and on scientific evidence, an important principle of VBP, and both naltrexone and topiramate are recommended by the American Psychiatric Association for the treatment of alcohol use disorders $[9,10]$. The treatment in this case serves exclusively as a tool for a harm reduction strategy as desired by the patient. It is, however, only a pharmacological harm reduction, since the patient does not accept a broader harm reduction, in which more restrictions would be included. The preference for narrow harm reduction strategies, usually pharmacological, is also a characteristic of Brazilian culture.

The patient's adherence to treatment was important, and the decision to base the choices on values resulted in a decrease in the impact of alcohol use, both in the difficulties previously seen in the social environment, as well as in better family 
and work relationships, and in the health care of Bruno, who now had direct contact with the health service and is aware of the risks he runs when he consumes alcohol.

Acknowledgements We wish to thank Bill Fulford for previous reading of this material. We also thank the Hospital do Servidor Público de Estadual de São Paulo for supporting this initiative.

\subsection{Guide to Further Sources}

- Woodbridge-Dodd K, Fulford KWM. Valores de Quem?. Tradução, adaptação e revisão técnica: Arthur Maciel Nunes Gonçalves The Sainsbury Centre for Mental Health 2004 (Brazilian Edition of british guide Whose Values?)

- The Brazilian VBP network. https://valuesbasedpractice.org/what-do-we-do/ networks/brazilian-vbp-network/

- The Committee of Alcohol Regulation (CRA) is a civil society initiative, led by Guilherme Messas, which brings together many stakeholders in the field of substance misuse. The aim of the Project is to offer and implement succesful regulatory measures for reducing the burden of alcohol use in Brazil. CRA uses value-based strategies for the development of its policies. See http://fcmsantacasasp.edu.br/cra/

- The VBP network for Co-production in Addiction. https://valuesbasedpractice. org/co-production-in-addiction-services/

\section{References}

1. Zaleski M, Pinsky I, Laranjeira R, Ramisetty-Mikler S, Caetano R. Intimate partner violence and alcohol consumption. Rev Saude Publica. 2010;44(1):53-9. https://doi.org/10.1590/ S0034-89102010000100006.

2. Brasil. Lei n ${ }^{\circ} .9294$, de 15 de julho de 1996. Coleção de Leis do Brasil. Diário Oficial da União 16 Jul 1996;1:13074.

3. World Health Organization. Global status report on alcohol and health-2014. Geneva: World Health Organization; 2014.

4. Messas GP, Silveira S, Maximiano V. A Hora e a Vez de uma Política do Álcool para o Brasil Orientada pela Saúde Pública (The time and place of a public health oriented alcohol policy for Brazil). RDM. 2019;2: RR-2.1-15.

5. Comitê para Regulação do Álcool (CRA) [Committee for Alcohol Regulation]. http:// fcmsantacasasp.edu.br/cra/. Accessed 5 Dec 2019.

6. Messas GP, Fukuda L, Pienkos E. A phenomenological contribution to substance misuse treatment: principles for person-centered care. Psychopathology. 2019;52(2):1-9. https://doi. org/10.1159/000501509.

7. Fulford KWM. Bringing together values-based and evidence-based medicine: UK Department of Health Initiatives in the "Personalization" of Care. J Eval Clin Pract. 2010;17(2):341-3. https://doi.org/10.1111/j.1365-2753.2010.01578.x. 
8. Macedo JP, Abreu MM, Fontenele MG, Dimenstein M. The regionalization of mental health and new challenges of the psychiatric reform in Brazil. Saúde Soc. 2017;26(1):155-7.

9. Fulford KWM. Values-based practice: a new partner to evidence-based practice and a first for psychiatry? Mens Sana Monogr. 2008;6(1):10-21.

10. Reus VI, et al. The American Psychiatric Association practice guideline for the pharmacological treatment of patients with alcohol use disorder. Am J Psychiatry. 2018;175(1):86-90.

Open Access This chapter is licensed under the terms of the Creative Commons Attribution 4.0 International License (http://creativecommons.org/licenses/by/4.0/), which permits use, sharing, adaptation, distribution and reproduction in any medium or format, as long as you give appropriate credit to the original author(s) and the source, provide a link to the Creative Commons license and indicate if changes were made.

The images or other third party material in this chapter are included in the chapter's Creative Commons license, unless indicated otherwise in a credit line to the material. If material is not included in the chapter's Creative Commons license and your intended use is not permitted by statutory regulation or exceeds the permitted use, you will need to obtain permission directly from the copyright holder.

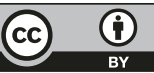

